\title{
A Critical Exploration of Abbas Ali Aboud's Novel Rites of Departure
}

\author{
Al Tayeb Al Nasri Mohammed Ahmed Abu Al Ghasim \\ Mukhwah Science and Arts College \\ Al Baha University, Al Baha, Saudi Arabia
}

\begin{abstract}
This study focuses on the novel 'Rites of Departure' by the Sudanese Abbas Ali Aboud (2009), most of the events took place at 'Alkawa' town. The study discusses the notion of vision, the impact of provincial towns on characters; events and human folklore highlighted in the novel. It deals with the novel in terms of prosaic and poetic content. The study concentrates on the relative analysis of events and the interrelations between characters and their controversial adventures, which are consistent historical philosophical and behavioral schools. This study attention primary and secondary characters within the novel, equally, factual and fictitious together with the sequence of incidents and its simultaneity with the denouement of this work. This critical study considers the chronological order of events with respect to the plot and the writer's conceptualization of the spatial, temporal backdrops and the nature of the dramatic that builds up the writer's unique world. This study employs the intertextuality approach in order to unveil the interstices and ambiguities of myth-laden utterances and sentences for a better explanation of their multiple meanings. The study concludes that regarding techniques, the novelist has in his evolving and multi-layered narrative innovatively appropriated some characteristics of Islamic mystic scholars in their enchantment with the mythical town. His descriptions are replete with verbal imagery that testify to an emotionless and a colorlessness which is linguistically reminiscent of mystical redemption. The novelist managed to merge a variety of artistic genres, including poetry, prose, and dramatic techniques that open new vistas as linguistic strategies.
\end{abstract}

Keywords: Abbas Ali Aboud, Alkawa, critical exploration, Rites of Departure

Cites as: Abu Al Ghasim, A. A. M. A. (2019). A Critical Exploration of Abbas Ali Aboud's Novel Rites of Departure. Arab World English Journal for Translation \& Literary Studies3 (4) 155- 162 DOI: http://dx.doi.org/10.24093/awejtls/vol3no4.13 